\title{
PÉREZ VILLAAMIL Y LOS INICIOS DEL ORIENTALISMO EN LA PINTURA ESPAÑOLA
}

\author{
POR \\ ENRIQUE ARIAS ANGLÉS \\ Departamento de Historia de Arte del CSIC
}

\begin{abstract}
According to the romantic european thought, the spanish historicism will be outlined on an archeological recovering seeking a national identity. In this context - where the romantic travellers played an important role toothe seed of our pictoric-orientalism developed herself.
\end{abstract}

El orientalismo artístico es un producto típico del romanticismo y, por consiguiente (por romántico y por europeo, por constituir, en definitiva, una visión desde nuestros propios presupuestos y prejuicios) un género falso en cualquiera de sus acepciones, pictórica, literaria, musical... Pero eso sí, terriblemente atractivo, como expresión sublimizada de uno de los mitos consoladores añorados por la crecientemente aburguesada civilización europea del siglo XIX, que encontró su vehículo idóneo de expresión precisamente en el romanticismo, curiosamente coincidente con el momento en que el expansionismo colonialista se encargaba de forzar las puertas de Oriente.

El proceso de descubrimiento e interés por el Oriente tuvo sus precedentes más inmediatos en el siglo XVIII, tanto en el pensamiento de la Ilustración como en el interés científico, plasmado en los viajes de exploración y descubrimiento de aquél siglo. Pero la realidad es que este proceso cultural estuvo íntimamente ligado a una política de expansionismo militarista de las potencias europeas, en progresivo aumento desde mediados del siglo XVII, y del que las expediciones científicas citadas de ese siglo no fueron más que una avanzadilla. Así, al hilo de una política expansionista y colonial, se abrió, en gran medida, el Oriente a los ojos de los europeos y progresivamente despertó su interés en ellos ${ }^{1}$.

En este proceso del descubrimiento de Oriente no hay que olvidar el caso de España, a la que los prejuicios románticos europeos llevaron forzadamente a jugar cierto papel en ello, papel determinado sin duda más por una falsa visión exterior que por un auténtico sentimiento incubado historicamente en su interior. Y no hay que olvidar, como decimos, el caso de España, por-

1 Arias Anglés, E.: «La pintura orientalista española. Imágen de un tópico», en La imágen romántica del legado andalusí, Barcelona-Madrid, 1995, pp. 47-48. 
que recien redescubierta al resto de Europa por medio de la guerra de la Independencia contra la invasión napoleónica, y sin ser tierra oriental, fue considerada a menudo, a pesar de ello, al igual que Venecia, como puerta de Oriente, pues guardaba los desvencijados y melancólicos recuerdos de una civilización oriental esplendorosa, ya casi olvidada, en cuya evocación se deleitaban los románticos por lo fascinante y novelesco de sus leyendas y por el triste destino de su destrucción, por su compendio de categorías de lo sublime, pues este melancólico recrearse en la remembranza de las civilizaciones perdidas era muy del gusto romántico; ya que el sujetivismo estético y emocionalismo románticos creía encontrar aquí, entre nosotros, un orientalismo español, más concretamente andaluz, convertido por los románticos en símbolo de una pretendida síntesis cultural entre lo europeo y lo islámico ${ }^{2}$; conceptos que, sustentados también por una especial iconografía, van a constituir una imágen de lo español y de lo andaluz, por demás falseada, en relación con el mundo musulmán.

Lo español - y lo andaluz en particular- se erige así en norma de la nueva simbología, de la nueva figuración histórica propiciada por las tendencias emocionalistas y arqueológicas, por el pensamiento historicista romántico, encarnando los nuevos valores que llenarían de significado sus pretensiones. Lo español, lo andaluz, auna de este modo el pintoresquismo a la poética de lo sublime, convirtiéndose así para la nueva mentalidad romántica en paradigma de paraiso perdido, en añoranza de un antiguo mundo armónico, que aún conservaba las cualidades misteriosas e iniciáticas de lo incógnito, que realizaba en plenitud las espectativas y aspiraciones del sujetivismo romántico sobre lo mágico y extraordinario, originando así un itinerario alternativo (el Spanish Tour) al tradicional Grand Tour británico de los clasicistas del siglo XVIII ${ }^{3}$ que, discurriendo por Francia y Suiza, culminaba en Italia, pues, como nos dice González Troyano, «Bien se quisiese evocar un determinado pasado, bien se quisiera recuperar un paraiso perdido, el entorno andaluz (...) posibilitaba un escenario con las huellas y referencias suficientes para dar pie a las ensoñaciones buscadas. Vestigios romanos, ruinas de castillos y monumentos árabes permitían recrear, según lo demandase la sujetividad del viajero, la antigüedad, el mundo del medievo, y sobre todo un Oriente artístico y literario (...) bien sustentado todo él con visibles y llamativos componentes exteriores y sin los inconvenientes, por otra parte, del largo desplazamiento exigido por el geograficamente verdadero./Esto último no dejaba de ser un recurso compesatorio que pudo estar en la base de esa afinidad electiva entre tantos viajeros y Andalucía. Los muchos ingredientes que componían su singularidad estaban relativamente próximos y una vez traspasados los Pirineos, y, aún más, Despeñaperros, era posible convencerse y transfigurar el mesurado exotismo que se contemplaba en otro más oriental, africano y salvaje (...).»4.

Se instaura así el mito de lo español, el mito de Al-Andalus, como elemento esencial del historicismo europeo, y del que, sin duda, fueron creadores en gran medida los viajeros ilustrados británicos que, como precursores, iniciaron este periplo hispano, convertido en iniciático por creer los románticos hallar en el mismo el prototipo de los nuevos ideales ${ }^{5}$.

$\mathrm{Ni}$ que decir tiene que el mito funcionó como superestructura cultural de la mentalidad, del ideario, historicista romántico, pero que fallaba por su propia base en cuanto que el contraste con la realidad española y andaluza del momento lo hacía insostenible al nivel de la praxis, pues, como igualmente precisa González Troyano, «Aunque un cierto inmovilismo predominase de

\footnotetext{
${ }^{2}$ Henares Cuéllar, I.: «Viaje iniciático y utopía: estética e historia en el romanticismo», en La imágen romántica del legado andalusí, Barcelona-Madrid, 1995, pp. 20 a 24.

3 Ibidem.

${ }^{4}$ González Troyano, A.: «Los viajeros románticos y la literatura costumbrista», en La imágen romántica del legado andalusí, Barcelona-Madrid, 1995, p. 37.

${ }^{5}$ Op. cit., nota 2, p. 22.
} 
forma más palpable en Andalucía que en esas otras partes de Europa que habían llevado a cabo sus revoluciones e incrementaban por aquellos años su industrialización, de todos modos era necesaria, por parte del viajero, una mirada, consciente o inconsciente, selectiva para eliminar lo que podía recordar la uniforme vida urbana europea y quedarse sólo con aquellas cosas factibles de dar cauce a lo que motivaba su nostalgia o su melancolía» ${ }^{6}$. De ahí que la mayoría de los viajeros románticos vieran, en este sentido, lo que querían, lo que venían predispuestos a ver, tal es la fuerza de los preconceptos, como acertadamente nos aclara también al respecto González Troyano al decirnos que «Se realiza, pues, un fenómeno de proyección idealizada, de recreación de un "otro" a la medida de las necesidades previas requeridas. De ahí que en el testimonio que se lleva a cabo cuente a veces más la propia invención de la subjetividad del viajero que el préstamo que posibilita el entorno visitado» ${ }^{7}$.

Este proceso cultural jugará importantísimo papel en la gestación de la pintura orientalista española, que no surge como respuesta a determinados imperativos de nuestro subconsciente histórico, como se ha pretendido ${ }^{8}$, sino que tiene su origen en una moda europea de carácter internacional consustancial al movimiento romántico, común a toda la cultura de Europa en el pasado siglo, respondiendo, por tanto, a los presupuestos básicos determinados por dicho movimiento, aunque tamizada por las interpretaciones de la propia idiosincracia nacional. Pues, basicamente, la burguesía culta española, sustentadora y consumidora de dicho producto, se situó ante el Oriente con los mismos o similares presupuestos que eran dictados por el romanticismo europeo, buscando la evasión exótica en el espacio y en el tiempo, en pos de la consoladora quimera, de la falaz ensoñación romántica, que parecía intuirse tras el exotismo y pintoresquismo de una civilización extraña.

El que los europeos viniesen a considerar en esta época a España casi como un país oriental y africano (tal sería el caso de Víctor Hugo), o como preludio de su soñado Oriente ${ }^{9}$, no quiere decir, ni muchisimo menos, que los españoles del romanticismo asumiesen, hiciesen suya, esta vertiente del mito, ya que este concepto (más diríamos prejuicio) no obedecía a un hecho real, sino que se había generado siguiendo los dictados de una preconcepción errónea, motivada por el propio romanticismo, que miraba a nuestra nación a través de los ensueños literarios que le proporcionaban una historia de enfrentamiento romántico con el Oriente, establecido durante siglos en nuestro propio suelo, y el exótico pintoresquismo de unos destacadísimos restos arquitectónicos que, en simbiosis con lo occidental, permanecían aún como testigos, como atractivas remembranzas, de ello, deviniendo en auténticos motores y promotores de dichos ensueños.

Sin embargo, y a pesar de lo dicho, los españoles aprendimos en determinadas ocasiones y aspectos, durante la época romántica, a vernos, en cierto modo y manera, con los mismos ojos con que nos veían, o querían vernos, los extranjeros, como ya hemos dicho en otra ocasión ${ }^{10}$, aunque ésto es más aplicable a nuestro pintoresquismo costumbrista, como apunta González Troyano ${ }^{11}$, que a una visión, desde luego no compartida, de un hipotético orientalismo nacional. La asunción por los propios españoles, aunque sólo fuese parcialmente, de la visión que los románticos europeos tenían de su país, elaborada fundamentalmente en función de una concepción

\footnotetext{
${ }^{6}$ Op. cit., nota 4, p. 37.

7 Ibidem.

${ }^{8}$ Sullivan, E. J.: «Mariano Fortuny y Marsal and orientalism in nineteenth-century Spain», Arts Magazine, abril de 1981, p. 96. Para mayor aclaración sobre este tema véase Arias Anglés, E.: «La pintura orientalista», en Pintura orientalista española (1830-1930), Fundación Banco Exterior, Madrid, 1988, pp. 32 a 34. Igualmente véase también op. cit., nota 1, pp. 49 y 50.

9 Victor Hugo en el prólogo de Les Orientales considera a España africana y oriental.

${ }^{10}$ Arias Anglés, E.: «Influencia de los pintores ingleses en España», en Imágen romántica de España, Ministerio de Cultura, Madrid, 1981, p. 88

${ }_{11}$ Op. cit., nota 4, pp. 43 a 45.
} 
visionaria y ensoñadora, es prueba de la incipiente fuerza cultural adquirida por el tópico, por el prejuicio.

La definición de un historicismo nacional, reflejo algo retrasado y más conservador con respecto al europeo, se va a producir entre nosotros, fundamentalmente, teniendo como base una reivindicación arqueológica en aras de la búsqueda de una identidad nacional, bajo los auspicios del moderantismo institucional reinante. De aquí, también, que la imágen romántica de España que se forman (y a su vez configuran) los intelectuales y artistas españoles, aunque en cierta medida dependa de la que nos proporcionan los extranjeros, sea, sin duda, bastante más moderada y costumbrista -teniendo su enmarque más paradigmático en lo andaluz-, adecuando el historicismo europeo al nacionalismo, a la tradición, de aquí el destacado papel que va a jugar entre nosotros el pintoresquismo. Este arqueologismo historicista y nacional se verá reflejado en la publicación de una serie de obras de carácter científico y pintoresco a la vez, planteadas desde diferentes actitudes culturales y que tienen su más inmediato precedente en la España Artística y Monumental, con dibujos de Pérez Villaamil y texto de Escosura; continuándose en obras como Recuerdos y Bellezas de España, con litografías de Parcerisa y textos de Piferrer y Pi y Margall entre otros; España. Sus Monumentos y Artes. Su Naturaleza é Historia, de Pedro de Madrazo y Francisco Pi y Margall; o El Museo Español de Antigüedades, de Rada y Delgado ${ }^{12}$. Son publicaciones en las que se pretende dar diferentes respuestas al problema de la recuperación nacional a través de los planteamientos arqueológicos e historicistas, donde, si bien se comienza a valorar y reivindicar el arte oriental de Al-Andalus, no se llega, a pesar de los planteamientos eclecticistas, a proporcionarle una total identidad nacional ${ }^{13}$.

Así, es dentro de este proceso de carácter internacional que, como vemos, tuvo su incidencia en la dinámica cultural interna de nuestro país, donde hay que situar la gestación y orígen de nuestra pintura orientalista, tanto a nivel general como más particular, mediante el influjo directo de algunos de los viajeros románticos que a España por entonces vinieron, buscando un tipo de orientalismo que sus preconceptos les llevaban a querer aquí encontrar. Tal sería el caso paradigmático y determinante de la fecunda relación establecida entre el pintor viajero escocés David Roberts - venido a nuestras tierras con el bagaje cultural del tópico aludido- y nuestro Jenaro Pérez Villaamil, como luego veremos.

De este modo, como decimos, ya desde sus inicios románticos, la pintura orientalista española inserta su cordón umbilical en su homónima europea, tanto por medio de la via estilística como por la subordinación al tópico de la temática, ya sea referente a la visión generalizada del mundo oriental como a la del perdido Al-Andalus, con claras alusiones en los asuntos de los cuadros, o por medio de la inserción en ellos de elementos arquitectónicos arabigo-españoles, ya con ánimo de fidelidad ya con una utilización meramente caprichosa, en órden a crear un elemento de fantasía.

12 Para una más amplia información sobre estos planteamientos véase op. cit., nota 2, pp. 25 a 27.

${ }_{13}$ Testimonio de ello tenemos en Francisco Pi y Margall: Granada, Jaén, Málaga y Almería, en España, Sus Monumentos y Artes - Su Naturaleza e Historia, Barcelona, 1885, donde, aún reivindicando al arte árabe andalusí, el progresista autor no se siente, sin embargo, identificado ni con el mismo ni con el pueblo que lo produjo, como lo prueban los numerosos comentarios que el escritor hace al respecto a lo largo de todo el texto del volumen y del que es buen ejemplo su afirmación - comentando la caida de Granada- de que «La gloria de los poderosos no logrará interesarme nunca como el llanto de los débiles por más que en aquellos vea á mis deudos y en éstos á mis enemigos» (p. 422), refiriéndose a los cristianos-europeos como a sus deudos y a los andalusies-musulmanes como a sus enemigos, por supuesto. Es decir, que el autor, aún partiendo de la idea «herderiana» de la igualdad entre las culturas (de ahí la reivindicación del arte andalusí), sin embargo su visión de la historia medieval de España sige siendo antinómica, como confrontación de dos culturas, ante lo que inevitablemente tiene que tomar partido. De hecho, como decimos, en más de una ocasión, Pi y Margall, refiriéndose al pasado de alguna de las ciudades andaluzas recogidas en ese tomo, califica a los árabes como sus «dominadores», lo cual es de lo más significativo en esta cuestión de identidades. 
Por tanto, de acuerdo con lo dicho, la pintura orientalista española arranca del romanticismo, donde tuvo su origen el orientalismo en general, como una moda europea de corte internacional, profundamente vinculada al movimiento romántico. Es decir, que el orientalismo español obedece a las mismas o muy semejantes causas que el resto de los orientalismos europeos.

Así, aparte los precedentes de carácter oriental que pudieran darse en el siglo XVIII, nada de extraño tiene que las primeras manifestaciones de pintura claramente orientalista aparezcan en los mismos inicios de nuestro romanticismo pictórico. Ya en 1833, cuando Jenaro Pérez Villaamil (1807-1854) ${ }^{14}$ abre, practicamente, la puerta de nuestra pintura romántica, este artista realiza un dibujo con Dos vistas fantaseadas de la Alhambra ${ }^{15}$, de inmediato, en 1834, pinta un óleo representado un Interior de la mezquita de Córdoba ${ }^{16}$, luego, en 1835, otros dos titulados Recuerdos de Granada ${ }^{17}$, y en 1836 otros con los temas de Puerta de ciudad árabe ${ }^{18}$, Ruinas y molinos en Alcalá de Guadaira ${ }^{19}$, Aspecto actual característico de las ciudades árabes en España ${ }^{20}$ y Un fragmento de Granada ${ }^{21}$, obras que se enmarcan en la revalorización romántica de nuestro patrimonio cultural, especialmente el árabe, en consonancia con el pensamiento historicista y ecléctico europeo - o sea, una reivindicación arqueológica en aras de la búsqueda de una identidad nacional- y que responden también a esa visión oriental de España (especialmente de Andalucía) que se inventaron los viajeros románticos europeos; obras, por lo tanto, significativas en cuanto al interés por el tema oriental. De hecho, de inmediato a estas producciones, en 1837, aparece ya una obra del pintor que entra plenamente dentro de lo que tradicionalmente entendemos como concepción más puramente orientalista (es decir, por lo que afecta al asunto en sí, a la temática general de la obra), nos referimos a la titulada Mercado árabe ${ }^{22}$ (Fig. 1), primer cuadro que le conocemos de semejante temática, lo que no quiere decir que sea el inicial que realizase de este tipo, pues bien pudo pintar algun otro anterior que hoy desconozcamos.

De hecho, y moviendonos dentro de los límites que nos ofrecen las obras fechadas o fechables que le conocemos en esta temática, Pérez Villaamil produjo cuadros de asuntos orientalistas a lo largo de toda su producción romántica, desde 1833 en que se inicia, como antes dijimos, hasta 1850 , cuatro años antes de su fallecimiento. Pero, como otras obras que le conocemos no se encuentran fechadas y otras más las sabemos sólo por referencias literarias, bien algunas de ellas pudieron ser coetáneas a la primera de las fechas referidas o posteriores a la segunda.

Sea como fuere, el hecho es que la producción hasta el presente conocida de pintura de tipo orientalista de Pérez Villaamil (bien se trate de asuntos tales en sí, bien referida a algún monumento de carácter oriental) es de unas cincuenta obras entre óleos, acuarelas y dibujos, computándose las más estrictamente orientalistas (o sea, las de tema puramente oriental) en torno a las

\footnotetext{
${ }_{14}$ Para mayor información sobre este pintor véase Arias Anglés, E.: El paisajista romántico Jenaro Pérez Villaamil, CSIC, Madrid, 1986.

${ }^{15}$ Dibujo a lápiz. Papel. 0,18 × 0,27 m. Inscripciones autógrafas: «En Granada/1833», sobre la vista de la izquierda; «Granada/Julio 1833», sobre la de la derecha. Museo de Pontevedra.

${ }^{16}$ Óleo. Firmado y fechado en 1834 (Arias Anglés, E.: op. cit., nota 14, p. 208, núm. 14).

17 Óleos. Exhibidos en 1835 en la exposición pública de pinturas de la Academia de San Fernando (Arias Anglés, E.: op. cit., nota 14, p. 210 , núms. 22 y 23 ).

18 Óleo. Tabla. 0,65 × 0,50 m. Firmado y fechado en 1836. Colección particular (Arias Anglés, E.: op. cit., nota 14, p. 211, núm. 25).

${ }_{19}$ Óleo. Exhibido en 1836 en la exposición de la Academia de San Fernando (Arias Anglés, E.: op. cit., nota 14, p. 212, núm. 28).

${ }_{20}$ Óleo. Exhibido en 1836 en la exposición de la Academia de San Fernando (Arias Anglés, E.: op. cit., nota 14, p. 212, núm. 32).

${ }^{21}$ Óleo. Exhibido en 1836 en la exposición de la Academia de San Fernando (Arias Anglés, E.: op. cit. nota 14, p. 213, núm. 36)

${ }^{22}$ Óleo. Lienzo. 0,53 ×0,53 m. Firmado y fechado en 1837. Colección particular (Arias Anglés, E.: op. cit.,nota 14, p. 215, núm. 43).
} 
veintiuna obras. Producción ésta, pues, de temática orientalista que sin alcanzar en número a la de Fortuny, pintor si no el más prolífico sí el más destacado de nuestro orientalismo, no deja de manifestar una impronta orientalista de cierta importancia en la producción del romántico gallego. Es por ello que Pérez Villaamil —además de ser el más importante paisajista romántico español, y el introductor de este género en la pintura española decimonónica, que es por lo que ha sido siempre conocido y afamado-, ha de ser igualmente considerado como pintor orientalista y, con seguridad, como el introductor también de este tipo de pintura entre nosotros.

Una vez sentado ésto, pasemos ahora a analizar de qué tipo fue el orientalismo practicado por Pérez Villaamil. Desde luego, se hace inevitable (al igual que al estudiar su tipo de paisajismo) la referencia al pintor romántico escocés David Roberts, a quien Pérez Villaamil conoció en $1833^{23}$ con motivo de su viaje artístico por España y Marruecos y de quien tomó el gallego su tipo de pintura. No hay duda de que Roberts fue un paisajista, pero tampoco se puede poner en duda que, dentro de los parámetros de su paisajismo, una parte destacada de su producción estuvo dedicada al tema oriental, como paradigma del pintor viajero que fue inquiriendo en las civilizaciones del mundo mediterráneo los exóticos paraisos perdidos anhelados por la sociedad de su época. Así, los asuntos orientalistas de Roberts fueron concebidos dentro de una visión paisajista, con especial incidencia en el monumento, adobada con anécdotas orientales, la mayoría de ellos basados en una realidad más o menos fantaseada o inmersos, por la forma de tratarlos, en una cierta atmósfera de ensueño. Esto es igualmente válido para el orientalismo de Pérez Villaamil, quien lo aprendió de Roberts y de los grabados de otros pintores y dibujantes británicos del momento bastante similares, con la única diferencia de que mientras Roberts viajó al Oriente, Pérez Villaamil, que sepamos, nunca lo hizo, ni siquiera a Marruecos. Pero ya fuese recurriendo a su fantasía o buscando inspiración en los grabados de los viajeros románticos de la época o en los restos arqueológicos orientalistas de la propia España, el orientalismo de Pérez Villaamil no difiere esencialmente del británico del momento, especialmente del de Roberts, al que más se asemeja.

De aquí que el primer orientalismo practicado en la España romántica sea de tinte británico y no francés, como pudiera parecer en principio más lógico. Sin embargo, la práctica de este tipo de pintura no podrá sustraerse por mucho tiempo al influjo galo, debido al fuerte contacto de la pintura española con la del país vecino y, posteriormente, el otro polo o eje sobre el que pivotará el orientalismo romántico español será el francés.

En líneas generales, como decimos, los cuadros orientalistas de Pérez Villaamil se enmarcan, al igual que los de Roberts, dentro de una concepción eminentemente paisajista. Es decir, la anécdota más o menos narrativa se halla inmersa en un ámbito bien sea puramente paisajista o concebido como tal, aunque se trate de un interior, o sea, privando en la composición el sentido general del ámbito sobre la anécdota que se diluye en el mismo.

Esta concepción tiene su más pura expresión en las obras que pueden ser consideradas casi estrictamente como paisajes, tales como Paisaje costero oriental (o Puerto oriental) ${ }^{24}$, Paisaje de África ${ }^{25}$, Paisaje oriental con puente fortificado ${ }^{26}$ (Fig. 2) o Paisaje con personaje oriental ${ }^{27}$, composiciones todas ellas eminentemente paisajistas en las que, junto a la anécdota concebida

\footnotetext{
${ }^{23}$ Arias Anglés, E.: «Relaciones entre David Roberts, Villaamil y Esquivel», Goya, núm. 158, 1980, pp. 66 a 69; Arias Anglés, E.: op. cit., nota 14, pp. 45 a 47.

${ }^{24}$ Óleo. Lienzo. Firmado y fechado en 1843 (?). Colección particular (Arias Anglés, E.: op. cit., nota 14, p. 241 , núm. 124 bis).

25 Óleo (Arias Anglés, E.: op. cit., nota 14, p. 266, núm. 196).

26 Óleo (Arias Anglés, E.: op. cit., nota 14, p. 267, núm. 202).

27 Óleo. Madera (?). 0,16×0,21 m. Colección particular (Arias Anglés, E.: op. cit., nota 14, p. 269, núm. 209).
} 

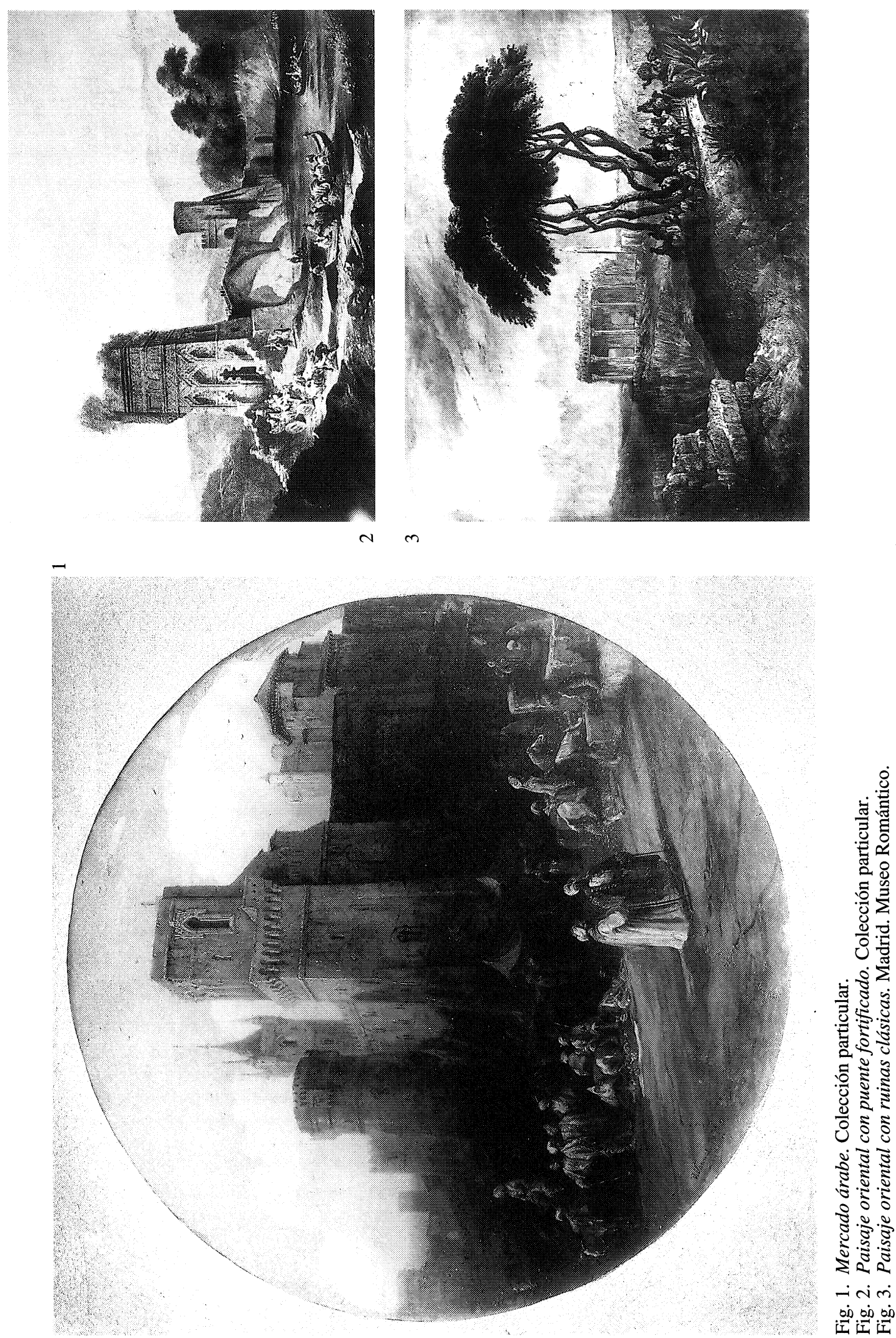
con personajillos orientales, suele destacar, normalmente hacia los primeros términos, la mole de alguna construcción fantástica de tipo oriental, subrayando así claramente el tipo de ambiente islámico que pretende representar.

Es, pues, éste el más claro ejemplo de esa concepción paisajística que, como decimos, campea en las composiciones orientalistas de Pérez Villaamil, y que es extensible a las demás temáticas que a continuación veremos, pero también es, a la vez, un asunto característico de la iconografía de la pintura orientalista: el paisaje oriental. Porque, hay que destacar también que ya en la pintura de Pérez Villaamil aparecen muchos de los temas que tipificaron a la iconografía de la pintura orientalista en general durante todo su desarrollo, ya que no hay que olvidar que el orientalismo fue un género con personalidad propia, poseyendo una peculiar iconografía y un sentido espectacular y brillante del colorido, características ambas asumidas por el orientalismo de Pérez Villaamil.

Así, junto al paisaje oriental ya referido, y en bastante proximidad a él, se encuentra otro de los temas típicos de la pintura orientalista: el desierto. Estas grandes soledades llamaron la atención de los viajeros y artistas europeos, sin duda por el contraste con la fertilidad de Europa, a la vez que ofrecían el romántico contrapunto a las ricas ciudades orientales y a los frondosos oásis. De este modo, esas llanuras desoladas, dominios del silencio, constituyeron para las románticas mentalidades una especie de imperio de la muerte ${ }^{28}$. Estas representaciones que tienen como motivo al desierto poseen dos vertientes. Una es la que, teniendo a estos grandes espacios desolados como telón de fondo, concede preeminencia a la representación de las ruinas del mundo de la Antigüedad, en torno a las cuales pululan personajes orientales, clara alusión a la nostalgia por las perdidas civilizaciones del pasado, tan del gusto romántico. Estas representaciones, heredadas de las ilustraciones de los libros de viajes del siglo XVIII ${ }^{29}$, constituyen una constante iconográfica de la pintura orientalista, en que el romántico contraste de las ruinas de una civilización que fue esplendorosa por las que pululan y acampan los nómadas del desierto, tiene cierto sentido pesimista y nostálgico, algo así como un «finis gloriae mundi» del romanticismo. A esta tipología con preeminencia de las ruinas de la antigüedad clásica y egipcia, tan del gusto de los orientalistas británicos, responden también claramente una serie de obras de Pérez Villaamil, como Paisaje oriental con ruinas clásicas ${ }^{30}$ (Fig. 3), Ruinas en las inmediaciones de Jerusalem ${ }^{31}$, Paisaje de Egipto con esfinge y pirámide ${ }^{32} \mathrm{o}$ Caravana a la vista de Tiro ${ }^{33}$, todas ellas composiciones fantásticas con inspiración en algún grabado. En la primera y en la última de estas obras se unen las dos vertientes indicadas anteriormente de esta iconografía del desierto tan características del orientalismo pictórico, la de las ruinas del pasado enmarcadas por el desierto y la de la caravana, asunto este último también tipico de la pintura orientalista y que pasamos igualmente a ejemlificar, en su forma más pura, en Pérez Villaamil a continuación.

Los beduinos nómadas que habitan estas soledades desérticas vinieron a representar para las románticas mentalidades europeas los últimos hombres libres ${ }^{34}$. Así, el desierto suele aparecer

${ }^{28}$ Jullian $\mathrm{Ph} .:$ Les orientalistes. La vision de l'Orient par les peintres européens au XIX siècle, Fribourg (Suisse), 1977, p. 94.

${ }^{29}$ Ibidem, pp. 103 y 104.

${ }^{30}$ Óleo. Lienzo. 0,78 × 0,96 m. Firmado y fechado en 1842. Museo Romántico. Madrid (Arias Anglés, E.: op. cit., nota 14 , p. 229, núm. 79).

${ }_{31}$ Óleo. Tabla. 0,52 ×0,71 m. Firmado y fechado en 1845. Patrimonio Nacional. Madrid (Arias Anglés, E.: op. cit., nota 14, p. 246 , núm. 143 ).

32 Óleo. Hojalata. 0,25 × 0,33 m. (Catálogo Sala Retiro de Caja de Madrid, marzo de 1997, p. 41, núm. 151 (reproducido con el título de Vista de esfinge y pirámide).

${ }^{33}$ Óleo. Lienzo. 0,97× 1,26 m. Firmado y fechado en 1846. Fundación Santamarca. Madrid (Arias Anglés, E.: Op. cit., nota 14 , p. 247 , núm. 145).

${ }^{34}$ Op. cit., nota 28, p. 96. 
unido a las figuras de estos nómadas que, para preservar su libertad, se vieron obligados a seguir los caminos de la desolación ${ }^{35}$. No son, sin embargo, muy abundantes los temas dedicados al desierto en la pintura orientalista española, que prefirió otros asuntos en esta temática, siendo Pérez Villaamil uno de los que más atención prestó a los espacios desolados y a las caravanas, como acabamos de ver, pudiendo lo ejemplificado ampliarse con dos obras más dedicadas exclusivamente al mundo de los beduinos nómadas y las caravanas, nos referimos a las tituladas Una caravana en el desierto ${ }^{36}$ (Fig. 7) y Caravana ${ }^{37}$, de las que nos es conocida la primera, donde se nos representa una hermosa vista del desierto por el que transita una caravana digna de la imaginación evocada por la lectura de Las mil y una noches.

Otro asunto típico de la iconografía orientalista fue el del mercado o zoco, cuyas variopintas concurrencia y actividad llamaron también profundamente la atención de los viajeros occidentales; lugares donde cabía la representación de la riqueza y el lujo al lado de la mayor de las miserias, tanto en los tipos como en las mercancías. Esta temática fue igualmente abordada por Pérez Villaamil, al menos en dos cuadros dedicados a tal asunto que le conocemos, uno de ellos titulado Mercado árabe ${ }^{38}$ y el otro Un zoco ${ }^{39}$ (Fig. 6). El primero de ellos es una composición de pura fantasía, tanto en las arquitecturas medievales del fondo (más de tipo gótico que islámico), al pié de las cuales se desarrolla el mercado, como en los personajes que por su carácter turco no se acuerdan con aquellas, estando sacados ambos elementos, sin duda, de diferentes grabados; mientras que el segundo, aún obedeciendo más a la realidad, ya que nos representa las galerías de un zoco o bazar turco, sigue denotanto, sin embargo también, su fuente de inspiración en un grabado.

La violencia constituyó otra de las temáticas predilectas del orientalismo. La crueldad arbitraria en el castigo o la venganza, unidas muchas veces a la sensualidad, depertaron sentimientos morbosos en la visión que los occidentales tenían del Oriente. Entre las diferentes manifestaciones de dicha violencia, ocupó lugar destacado la de las ejecuciones, concebidas en el mundo oriental de forma solemne, a modo de fiestas públicas ${ }^{40}$. Si bien Pérez Villaamil eludió la representación de la violencia en relación con la sensualidad (lo que, por otra parte era muy dificil de expresar con su tipo de pintura), no soslayó, sin embargo, este elemento iconográfico del orientalismo, dejándonos prueba de ello en un cuadro titulado Una ejecución en la Tierra Santa ${ }^{41}$ que, aunque hoy dia ignoramos su paradero, el carácter eminentemente descriptivo de su título es suficientemente representativo para adscribirlo a la citada iconografía.

El tema histórico de carácter oriental, tanto de la actualidad como del medievo o la antiguiedad, fue otra de las temáticas abordadas por el orientalismo pictórico y literario. No se sustrae tampoco Pérez Villaamil — a pesar de su adscripción tradicional al paisajismo- a los asuntos históricos, que fueron preludio, en el romanticismo español, a la gran eclosión de la pintura de historia de la segunda mitad del siglo XIX, aunque, si bien es verdad los aborda con la concepción general paisajística que dominó en su tipo de pintura. Pero, lo curioso es que, por las obras que le conocemos, lo trató esencialmente dentro de la iconografía orientalista y con temas tanto de la historia nacional como de carácter internacional.

\footnotetext{
${ }^{35}$ Ibidem.

${ }^{36}$ Óleo. Lienzo. 0,97×1,29 m. Fundación Santamarca. Madrid (Arias Anglés, E.: op. cit., nota 14, p. 270, núm. 217).

${ }^{37}$ Óleo. Arias Anglés, E.: op. cit., nota 14, p. 265, núm. 191.

${ }^{38}$ Vid. nota 22.

${ }^{39}$ Óleo. Lienzo. 0,515 × 0,715 m. Firmado. Colección particular (Arias Anglés, E.: op. cit., nota 14, p. 288, núm. 289).

${ }^{40}$ Op. cit., nota 28 , p. 80.

${ }^{41}$ Óleo. Exhibido en 1849 en la exposición de la Academia de San Fernando (Arias Anglés, E.: op. cit., nota 14, p. 254, núm. 159).
} 


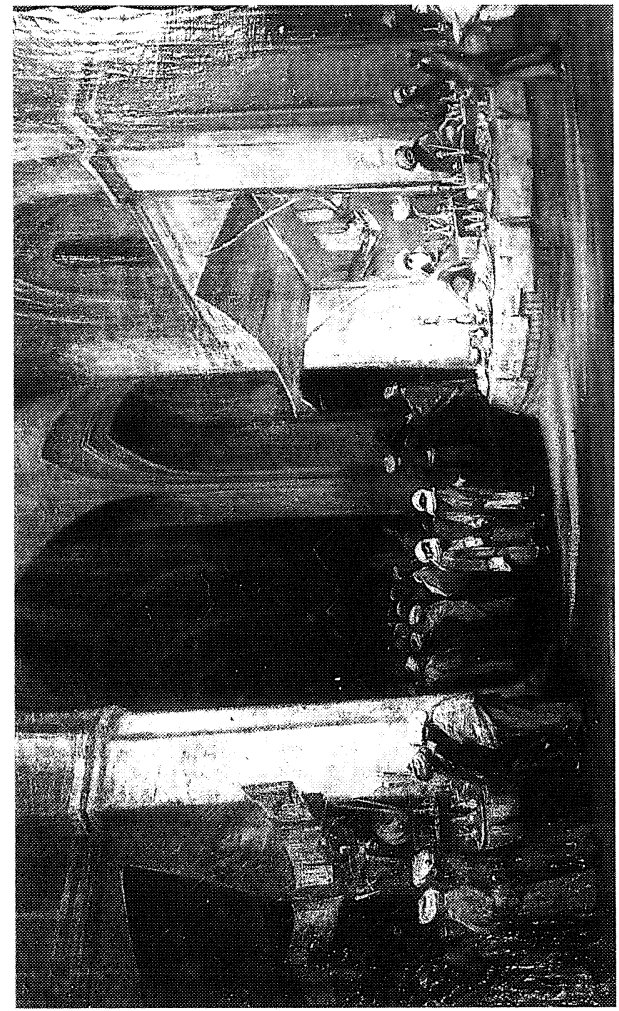

6

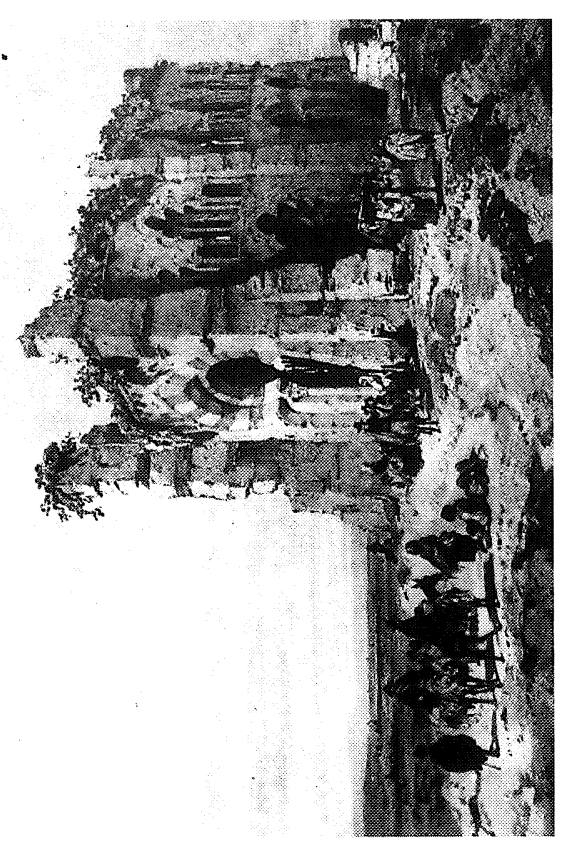

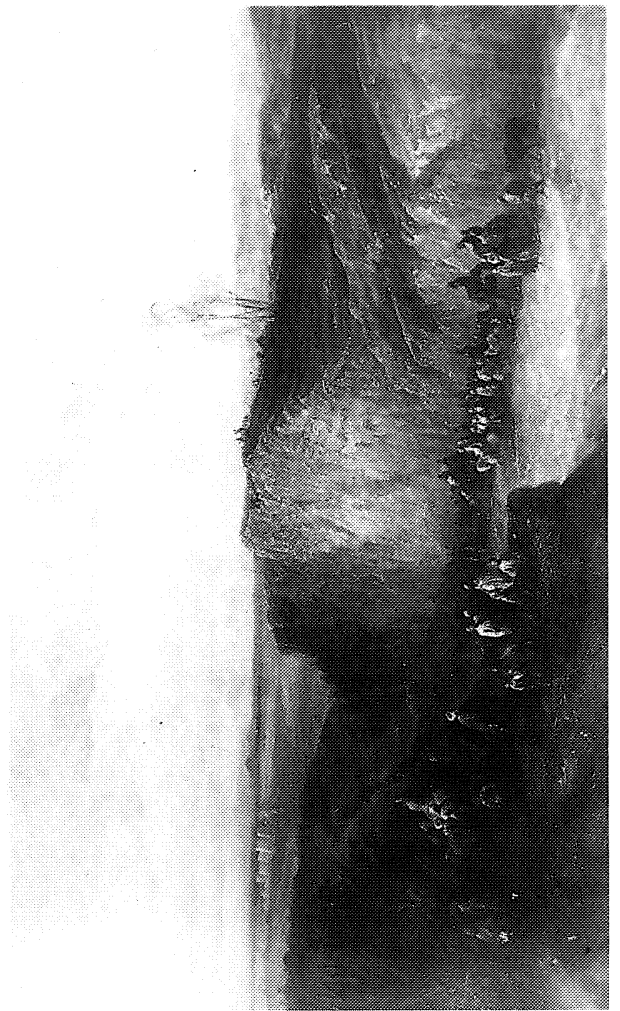

$N$

n

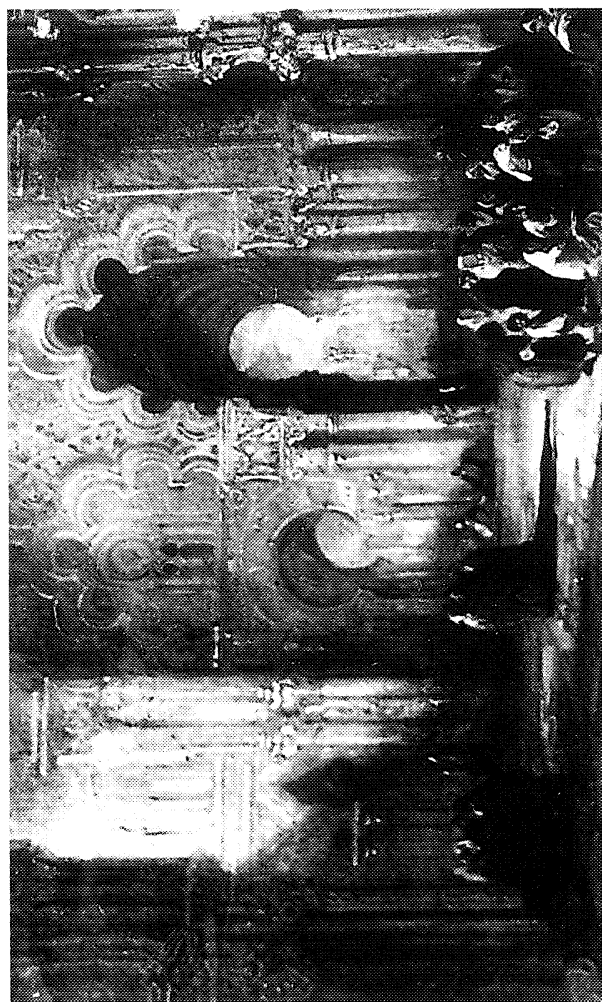


Dentro de la temática nacional pintó El juramento de Álvar Fáñez de Minaya (o Álvar Fá$\tilde{n} e z$ de Minaya después de la conquista de Cuenca $)^{42}$, cuadro de una desbordada fantasía morisca, en el que la imaginación del pintor nos representa un interior de un palacio árabe en el que se mezclan los elementos arquitectónicos de estirpe marroquí con los de estilo nazarita, destacando, de la vista exterior que se nos muestra a través de un amplio pórtico, un minarete de tipo mameluco egipcio, estando todo el ámbito poblado por multitud de personajes musulmanes y cristianos.

Los otros dos cuadros que le conocemos de esta temática de historia orientalista representan asuntos de las Cruzadas, con los títulos de Los cruzados descubriendo la ciudad de Jerusalem ${ }^{43}$ y La toma de Jerusalem por Godofredo de Bouillon ${ }^{44}$, obras que nos son hoy día conocidas sólo por referencias literarias, pero cuyos descriptivos títulos son los suficientemente significativos para poder incluirlos en esta vertiente iconográfica orientalista. Resulta un poco extraña la elección de estos dos últimos asuntos de la historia de las Cruzadas cuando, salvo raras excepciones (caso de Gisbert con sus Puritanos, por ejemplo, y había para ello una razón política), los asuntos de los cuadros de historia solían estar sacados de la historia nacional. La única razón que se nos ocurre - entre otras muchas que pudieron ser- es la coincidencia de temática (Godofredo de Bouillon) con el cuadro que Federico de Madrazo pintó en 1838 por encargo del rey Luis-Felipe para Versalles, representando a Godofredo de Bouillon proclamado rey de Jerusalem ${ }^{45}$, cuadro que pudo haber conocido Pérez Villaamil entre 1840 y 1844, cuando marchó a Francia y Bélgica. De hecho, Pérez Villaamil y Federico de Madrazo mantuvieron una cierta relación de amistad ${ }^{46}$ - a pesar del desprecio del clan de los Madrazo hacia el romanticismo que representaron los artistas del círculo del Liceo Artístico y Literario ${ }^{47}$, entre cuyos creadores estaba Pérez Villaamil - y quizá ello le animó a emprender también algún cuadro sobre el tema de las Cruzadas, si bien bajo el enfoque y tratamiento bien distintos que exigía su tipo de pintura.

Aún se plegaría más Pérez Villaamil a la incipiente iconografía orientalista, realizando cuadros alusivos a un orientalismo de carácter español que el sujetivismo estético y emocionalismo romántico, como dijimos, creía encontrar entre nosotros y que devino para los románticos europeos en símbolo de una pretendida síntesis cultural, concepto que, apoyado en una determinada iconografía, iba a proporcionar una imágen falseada de lo español, entrando así en el juego en que lo español se erigía en norma de la nueva simbología, de la nueva figuración histórica propiciada por las tendencias emocionalistas y arqueológicas, por el pensamiento historicista romántico. Pérez Villaamil, siguiendo la pauta del español culto del romanticismo, se sitúa ante los restos arqueológicos islámicos de nuestro país con semejante ánimo al de cualquier otro europeo del momento, contemplándolos como unos vestigios arqueológicos profundamente imbricados en la mitología orientalista de carácter internacional, con el talante elegíaco de la poética de las ruinas. Contribuye así nuestro artista, con esta, en cierto modo, aceptación de la visión que de nosotros tenían los románticos europeos, a incorporar al acervo cultural hispano ese mito de lo español, a que nos hemos referido, creado por el historicismo europeo, aunando el pintoresquismo a la poética de lo sublime. Y ésto no es sólo aplicable a nuestro pintoresquismo ar-

${ }^{42}$ Óleo. Lienzo. 1,46 × 2,23 m. Firmado y fechado en 1847. Patrimonio Nacional. Madrid (Arias Anglés, E.: op. cit., nota 14 , p. 248 , núm. 148 )

${ }_{43}$ Óleo. Perteneció a la colección de los duques de Montpensier (Arias Anglés, E.: op. cit., nota 14, p. 277, núm. 244).

${ }^{44}$ Óleo. Exhibido en 1850 en la exposición de la Academia de San Fernando (Arias Anglés, E.: op. cit., nota 14, p. 256, núm. 165).

${ }^{45}$ Óleo. Lienzo. $1,96 \times 1,36 \mathrm{~m}$. Firmado y fechado en 1838. Musée National du Château de Versailles. Versalles (catálogo exposición Federico de Madrazo y Kuntz (1815-1894), Museo del Prado. Madrid, 1995, p. 152, núm. 10).

${ }^{46}$ Arias Anglés, E.: op. cit., nota 14, p. 82.

${ }^{47}$ Ibidem, pp. 152 y 153. 
quitectónico, sino que también es extensible al período histórico de dominio musulmán sobre AlAndalus. La burguesía española, profundamente influida por la europea, y a la moda de los productos culturales que ésta producía, miraba, por tanto, los restos de la cultura islámica de la península Ibérica con ojos similares a los de Europa. En ésto Pérez Villaamil va a contribuir a la definición de ese historicismo nacional a que antes aludimos, teniendo como plataforma una reivindicación arqueológica en aras de la búsqueda de una identidad nacional, pero, como dijimos, configurando una visión de España de carácter más moderado y costumbrista, más pintoresca, producto de la adecuación del historicismo europeo al nacionalismo.

Así, como decimos, Pérez Villaamil se pliega, matizadamente, a esta modalidad iconográfica del orientalismo europeo, entrando, en cierto modo, en su juego con representaciomes como las anteriormente citadas de Dos vistas fantaseadas de la Alhambra, Interior de la mezquita de Córdoba (Fig. 5), Recuerdos de Granada, Puerta de ciudad árabe, Ruinas y molinos en Alcalá de Guadaira, Aspecto actual característico de las ciudades árabes en España y Un fragmento de Granada $^{48}$, a las que añadiríamos otras como Vista de la Giralda de Sevilla desde la calle de la Borceguinería ${ }^{49}$ (Fig. 8), Un interior de la catedral de Córdoba ${ }^{50}$, Fragmento de fortificación $a^{\text {rabe }}{ }^{51}$ (Fig. 12), Un interior árabe ${ }^{52}$, El castillo de Alcalá de Guadaira ${ }^{53}$, La puerta árabe ${ }^{54}$, El castillo de Gaucin ${ }^{55}$, otra Puerta de ciudad árabe ${ }^{56}$, Fantasía de la Alhambra ${ }^{57}$, Antigua fortaleza hispano-musulmana ${ }^{58}$, otro Interior de la catedral de Córdoba ${ }^{59}$, Interior hispano-musulmán (Fig. 13) ${ }^{60}$, otro Interior árabe ${ }^{61}$, Vista de la catedral de Córdoba ${ }^{62}$, Portada toledana mudéjar con dos personajes ${ }^{63}$, Restos de construcción mudéjar en Humanejos (Madrid) ${ }^{64}$ (Fig. 4), Interior de Santa María la Blanca de Toledo ${ }^{65}$ (Fig. 10),Taller del Moro, en Toledo ${ }^{66}$

48 Vid notas 15 a 21 .

49 Existen dos versiones de este asunto: $1^{\circ}$ ) Óleo. Lienzo. 0,82 $\times 0,61 \mathrm{~m}$. Firmado y fechado en 1833 . Colección particular (Arias Anglés, E.: op. cit., nota 14, p. 207, núm. 12); . $^{\circ}$ ) Óleo. Lienzo. 0,760 × 0,605 m. Firmado y fechado en 1838. Colección particular (Arias Anglés, E.: op. cit., nota 14, p. 221, núm. 57).

50 Óleo. Lienzo. $1,13 \times 0,88$ m. Perteneció a la colección del rey Luis-Felipe de Francia (Arias Anglés, E.: op. cit., nota 14, p. 221, núm. 56).

51 Óleo. Lienzo. 1,46 × 1,10 m. Exhibido en 1838 en la exposición de la Academia de San Fernando. Museo Nacional de Bellas Artes. Buenos Aires (Arias Anglés, E.: op. cit., nota 14, p. 226, núm. 72).

52 Óleo (?). Pintado en Lovaina (Bélgica) en 1843 (Arias Anglés, E.: op. cit., nota 14, p. 233, núm. 90).

53 Óleo. Lienzo. 1,10× 1,445 m. Firmado y fechado en 1843. Museo Nacional de Bellas Artes. Buenos Aires (Arias Anglés, E.: op. cit., nota 14, p. 239, núm. 115). El artista pintó otras dos versiones de este asunto (Arias Anglés, E.: op. cit., nota 14 , p. 239 , núms. 114 y 116$)$.

54 Óleo. Pintado en 1843 (Arias Anglés, E.: op. cit., nota 14, p. 240, núm. 119).

55 Existen tres versiones de este asunto: $\left.1 .^{a}\right)$ Óleo. Lienzo. 1,47 $\times 2,25 \mathrm{~m}$. Firmado y fechado en 1849 . Museo del Prado. Madrid (Arias Anglés, E.: op. cit., nota 14, p. 253, núm. 158); 2. ${ }^{\text {) }}$ Óleo. Lienzo. 1,05×0,735 m. Firmado. Museo Nacional de Bellas Artes. Buenos Aires (Arias Anglés, E.: op. cit., nota 14, p. 266, núm. 194); 3. a) Arias Anglés, E.: op. cit. nota 14, p. 242 , núm. 126.

56 Óleo. Lienzo. 0,76×0,60 m. Firmado (Arias Anglés, E.: op. cit., nota 14, p. 271, núm. 220).

57 Óleo. Tabla. 0,21 × 0,285 m. Colección particular (Arias Anglés, E.: op. cit., nota 14, p. 274, núm. 230).

58 Óleo. Arias Anglés, E.: Op. cit. nota 14, p. 274, núm. 231.

59 Óleo. Tabla. $0,13 \times 0,16 \mathrm{~m}$ (Arias Anglés, E.: op. cit., nota 14, p. 279, núm. 249).

${ }^{60}$ Óleo. Lienzo. 0,27 × 0,22 m. Museo Nacional de Bellas Artes. Buenos Aires (Arias Anglés, E.: op. cit., nota 14, p. 282, núm. 262).

${ }^{61}$ Óleo. Miniatura (Arias Anglés, E.: op. cit., nota 14, p. 282, núm. 263).

62 Óleo (Arias Anglés, E.: op. cit., nota 14, p. 291, núm. 297).

63 Acuarela con dibujo. Papel. 0,26×0,19 m. Firmada y fechada en 1840. Colección particular (Arias Anglés, E.: op. cit., nota 14, p. 296, núm. 316).

${ }^{64}$ Acuarela con dibujo. Papel. 0,20 × 0,26 m. Firmada y fechada en 1840. Colección particular (Arias Anglés, E.: op. cit., nota 14, p. 297, núm. 319).

65 Aguada (Arias Anglés, E.: op. cit., nota 14, p. 337, núm. 452).

${ }^{66}$ Aguada con dibujo. Papel. 0,29 ×0,38 m. Firmada. Colección particular (Arias Anglés, E.: op. cit., nota 14, p. 339, núm. 458). 

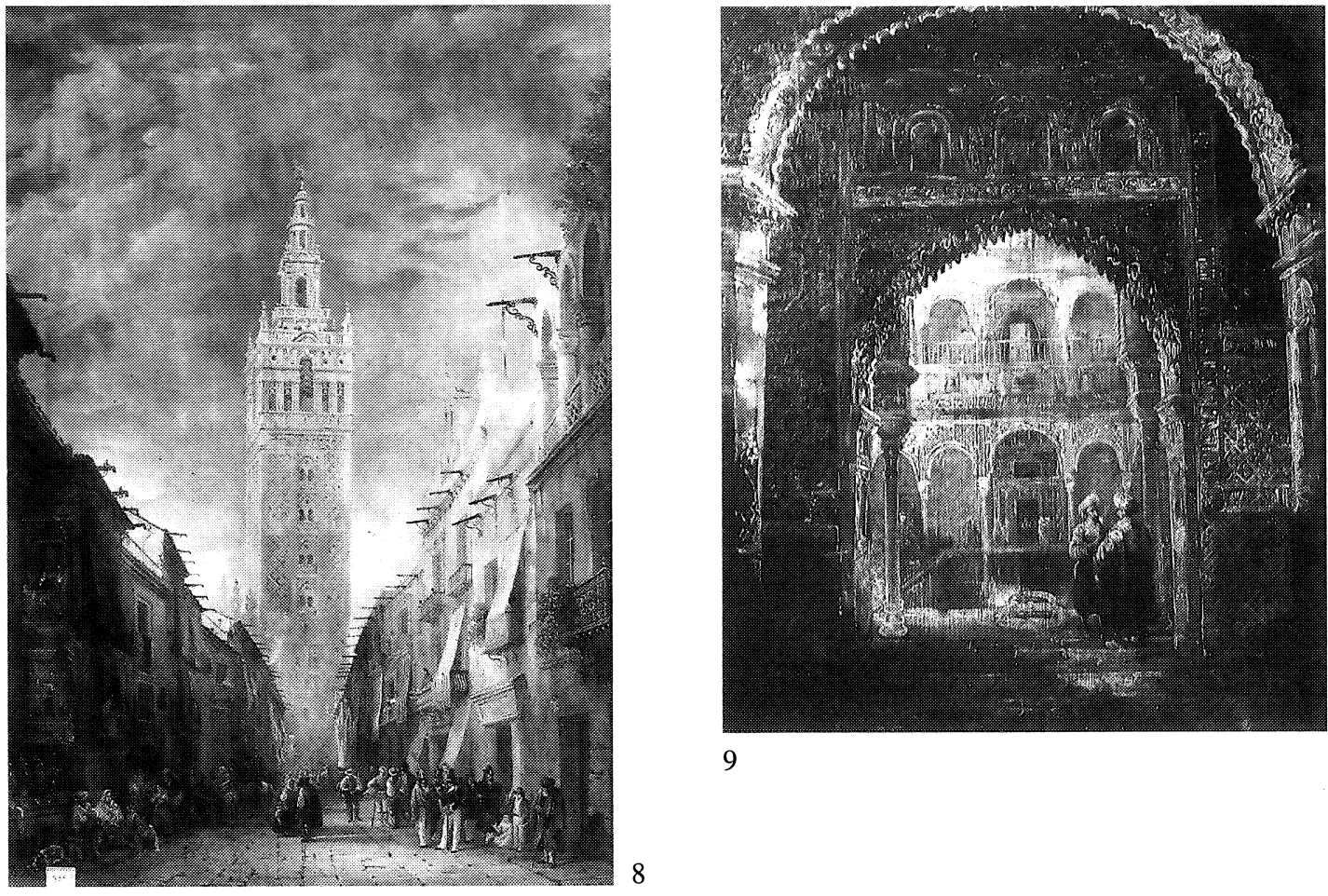

9

8

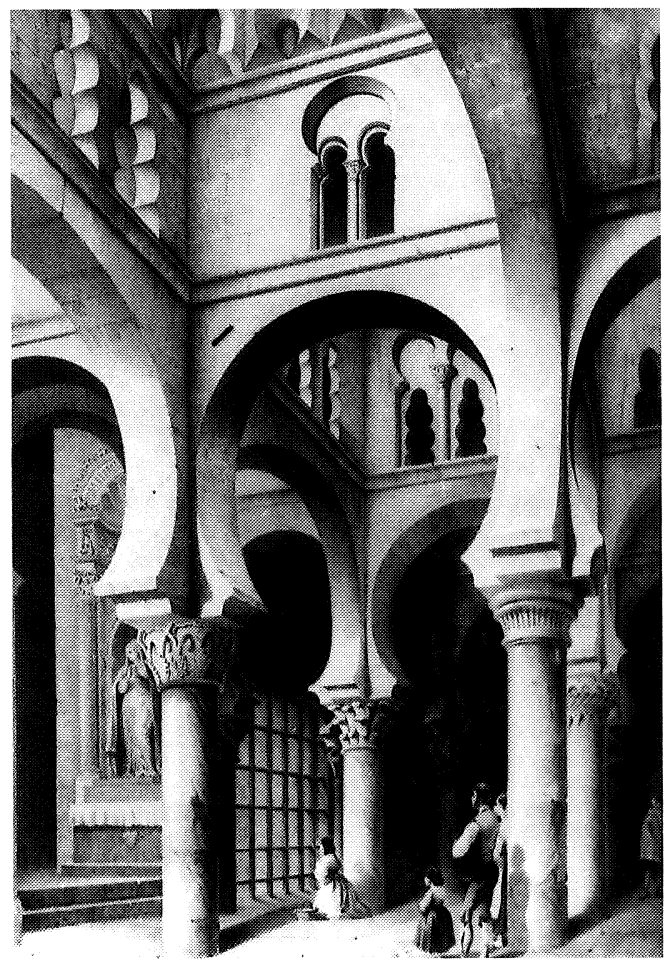

11

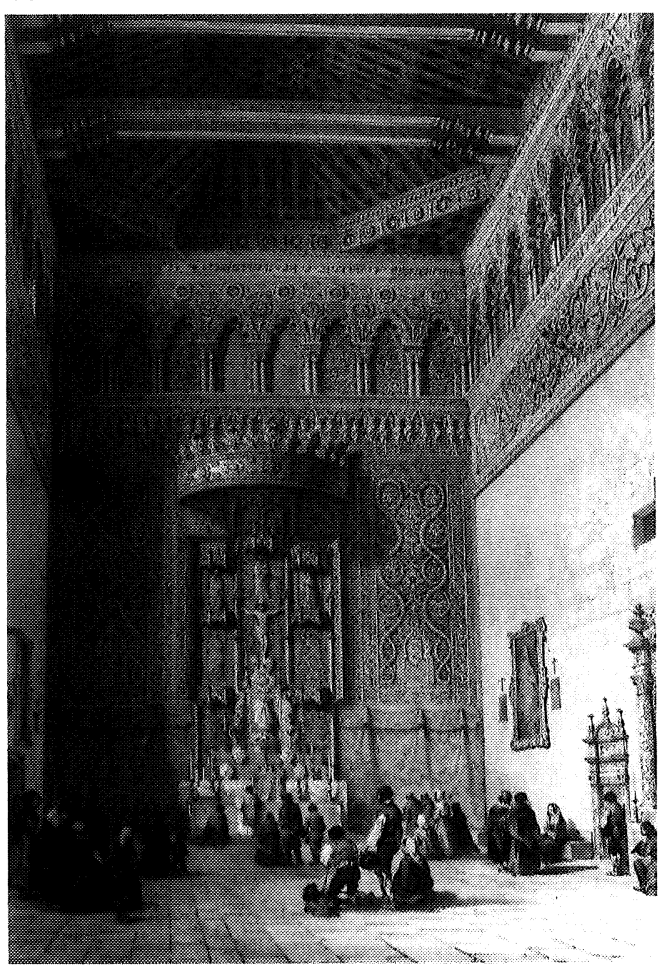

Fig. 8. Vista de la Giralda. Colección particular.

Fig. 9. Vista del patio de Comares de la Alhambra. Colección particular.

Fig. 10. Interior de Santa María la Blanca. Litografía de la «España Artística y Monumental».

Fig. 11. Interior de la sinagoga del Tránsito. Litografía de la «España Artística y Monumental». 

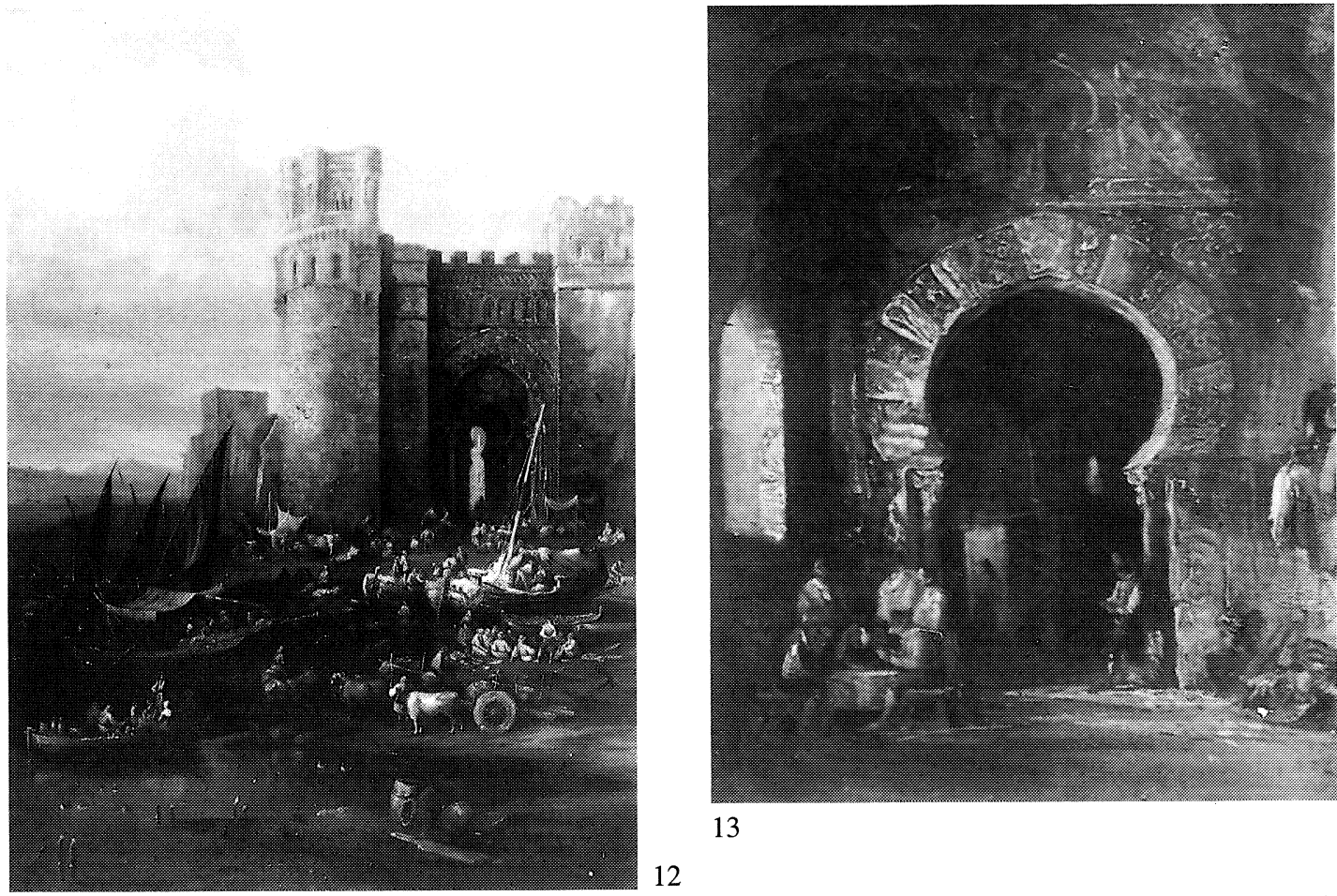

13

12

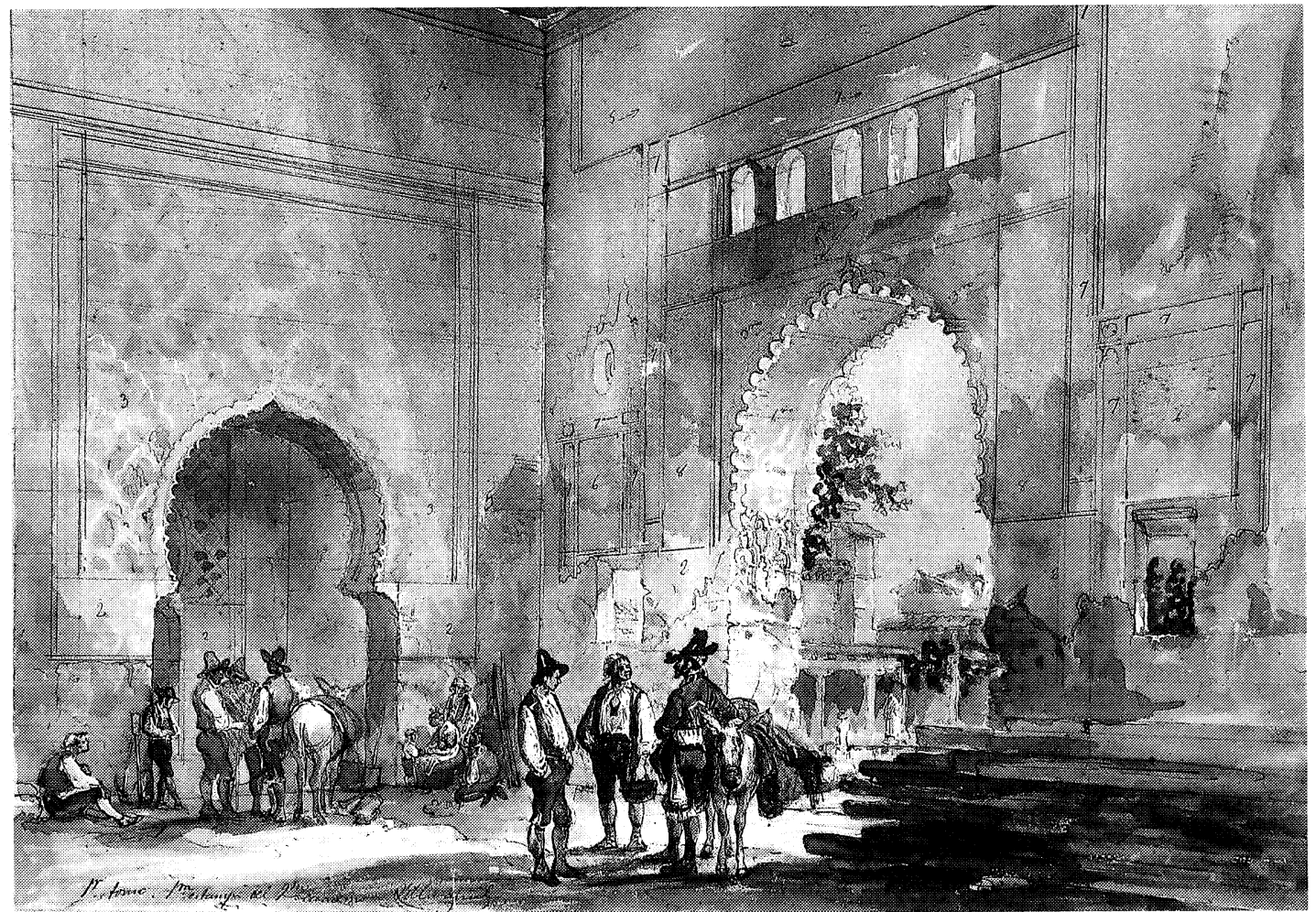

Fig. 12. Fragmento de fortificación árabe. Buenos Aires, Museo Nacional de Bellas Artes.

Fig. 13. Interior hispano-musulman. Buenos Aires, Museo Nacional de Bellas Artes.

Fig. 14. Taller del Moro. Colección particular. 
(Fig. 14), Interior de la sinagoga del Tránsito de Toledo ${ }^{67}$ (Fig. 11), La puerta de Serranos de Valencia ${ }^{68}$, o Capitel musulmán (Toledo) ${ }^{69}$, entre otras más que harían prolija esta relación; obras en las que el orientalismo está representado, en general, por el monumento en sí adobado con el pintoresquismo costumbrista de la España del momento, y que, como decimos, se enmarcan en la revalorización romántica de nuestro patrimonio cultural en busqueda de la definición de un historicismo nacional, respondiendo, por tanto, a la visión oriental de España que tuvieron los románticos europeos. Junto a éstas y con un sentido más estrictamente orientalista (por lo que respecta al asunto en sí), pero obedeciendo a los mismos postulados expuestos, tenemos obras como Sevilla en tiempo de los árabes ${ }^{70}$, Vista del patio de Comares de la Alhambra de Granada ${ }^{71}$ (Fig. 9) y otra más sobre La puerta de Serranos de Valencia ${ }^{72}$, donde el orientalismo, además de centrarse en la arquitectura, se ambienta en la época medieval musulmana de Al-Andalus, con personajes orientales, camellos y otros elementos que, más o menos fantasedos todos, pretenden recrearnos el ambiente oriental de aquella época.

Y aún tendríamos que citar un par de obras orientalistas más de Pérez Villaamil que, al sernos sólo conocidas por referencias y debido además a la ambigüedad de sus títulos, no podemos ubicar en ninguna de las vertientes iconográficas de este tipo de pintura; nos referimos a las tituladas Jerusalem ${ }^{73}$ y Personajes árabes ${ }^{74}$, de las que nos limitamos a dejar constancia de ellas como tales obras orientalistas a sumar al catálogo de las de este tipo realizadas por el romántico gallego.

Vemos, pues, que Pérez Villaamil, además de su principal y conocidisima dedicación paisajística, reune las condiciones necesarias para ser considerado también un orientalista, tanto por el volumen de su obra dedicada a este tipo de pintura como por los diferentes resortes iconográficos que toca de la misma. Si bien es verdad que no los presiona todos, ya que iconografías tan características del orientalismo como la religiosidad, los sultanes, los tesoros, los esclavos, las odaliscas y los harenes, la sensualidad en general, no aparecen en su obra, quizá porque escapaban al tipo de pintura por el artista practicado o tenían dificil imbricación en ella, y ésto a pesar del testimonio que de su dedicación orientalista pretende darnos su amigo el poeta Zorrilla en los versos que al pintor le dedica, en los que nos dice: «Tú tienes dentro la mente/.../todo el lujo del oriente/.../pintarás.../los alcázares morunos/.../Pintarás los gabinetes/cincelados de la Alhambra/y el humo de los pebetes/y las bellas del harén» ${ }^{75}$, versos que, aparte de ofrecernos un irrefutable testimonio literario de la dedicación orientalista de Pérez Villaamil y que por tal pintor orientalista también se le tenía, creo se exceden también literariamente un poco en cuanto al abanico iconográfico ofrecido por la pintura de este tipo practicada por nuestro pintor, ya que, en la producción que le conocemos, ni hemos visto «el humo de los pebetes» y ni mucho menos «las bellas del harén», quizá, como decimos, porque la sensualidad escapaba al tipo de pintura en que vertió su orientalismo Pérez Villaamil. Tomémoslo pués, entre tanto no aparezcan testimonios gráficos, como una licencia literaria.

\footnotetext{
${ }^{67}$ Dibujo a pluma. Papel. Fechado en 1840. Colección particular (Arias Anglés, E.: op. cit., nota 14, p. 349, núm. 490).

${ }^{68}$ Dibujo (Arias Anglés, E.: op. cit., nota 14, p. 385, núm. 651).

${ }^{69}$ Dibujo a lápiz. Papel. $0,17 \times 0,255$ m. Museo de Pontevedra (Arias Anglés, E.: op. cit., nota 14, p. 404, núm. 714).

70 Óleo. Lienzo. 0,95 × 1,25 m. Firmado y fechado en 1848. Patrimonio Nacional. Madrid (Arias Anglés, E.: op. cit., nota 14, p. 251, núm. 153).

${ }^{71}$ Óleo. Lienzo. 0,57 ×0,505 m. Firmado. Colección particular (Arias Anglés, E.: op. cit., nota 14, p. 287, núm. 284).

72 Óleo. Lienzo. 0,75 × 0,65 m. Firmado. Exhibido en 1838 en la exposición del Liceo Artístico y Literario Español de Madrid. Museo Romántico. Madrid (Arias Anglés, E.: op. cit., nota 14, p. 227, núm. 74.

${ }_{73}$ Óleo. Arias Anglés, E.: op. cit., nota 14, p. 263, núm. 183.

${ }^{74}$ Óleo. Hojalata. 0,18 ×0,13 m. Colección particular (Arias Anglés, E.: op. cit., nota 14, p. 290, núm. 296).

75 Poesía autógrafa de José Zorrilla, titulada La noche de invierno, dedicada a Jenaro Pérez Villaamil, firmada y fechada el 28 de septiembre de 1837. Seis páginas y media de papel de carta. Pertenece a los descendientes del pintor (Arias Anglés, E.: op. cit., nota 14, p. 440, núm. 18).
} 